\title{
Isolation and characterisation of a panel of cosmids which allows unequivocal identification of chromosome deletions involving the RB1 gene using fluorescence in situ hybridisation
}

\author{
John K Cowell, Rina Jaju, Helena Kempski
}

\begin{abstract}
A series of cosmids covering the majority of the RB1 gene have been isolated from a flow sorted human chromosome 13 specific library. Using fluorescence in situ hybridisation these cosmids were all shown to hybridise to the $13 q 14$ region but not to chromosomes known to carry subband deletions involving the RB1 gene. This panel of cosmids, therefore, can be used objectively for identification of RB1 gene deletions in tumour and normal cells.
\end{abstract}

(F Med Genet 1994;31:334-337)

The retinoblastoma predisposition gene has been unequivocally assigned ${ }^{1}$ to the $13 \mathrm{q} 14$ region by linkage to the esterase $\mathrm{D}$ gene (ESD). This localisation had long been suspected $^{23}$ because of the observation of constitutional 13q14 deletions in some retinoblastoma $(\mathrm{Rb})$ patients. Approximately $3 \%$ of $\mathrm{Rb}$ patients carry constitutional $13 \mathrm{q} 14$ abnormalities. ${ }^{4}$ Although the majority of these patients have extensive chromosome deletions, which result in a variety of associated congenital abnormalities, a few carry only subband deletions which could only be detected using high resolution chromosome banding techniques. Although severe mental retardation and dysmorphic features are usually associated with patients with large deletions involving $13 \mathrm{q} 14,5$ which is usually a sufficient indicator of the presence of such a deletion, patients with small, subband deletions may have very few associated phenotypes. We have shown previously that, on occasion, these small deletions may be overlooked using conventional trypsin-Giemsa banding procedures in routine laboratories. ${ }^{6}$ It is also possible that there are constitutional deletions, as yet undetected, which involve only the RB1 gene or even part of it which cannot be detected cytogenetically. We have reported one case, for example, of a partial intragenic deletion of the $\mathrm{RB} 1$ gene using conventional restriction fragment length polymorphism analysis. ${ }^{7}$ This deletion was only detected by chance because it involved two of the adjacent polymorphic loci used routinely in linkage analysis. Evidence of small intragenic deletions of the RB1 gene in tumours has also been reported. ${ }^{8}$

In the UK, $\mathrm{Rb}$ patients are routinely analysed cytogenetically since the presence of a chromosome deletion means that, in the future, prenatal screening of subsequent children is possible in these families. With the development of fluorescence in situ hybridisation (FISH) technology, which shows the presence of DNA sequences directly on metaphase chromosomes, the unequivocal existence of deletions of the RB1 gene can be established. If these deletions are restricted to the RB1 gene they will not be associated with congenital abnormalities which might otherwise identify these patients. Furthermore, since deletions do not affect fertility they can be passed on through the generations. In fact, these deletions will also be missed in screening programmes designed to identify mutations by sequencing ${ }^{910}$ since only the normal allele will be present in constitutional cells. To this end we have isolated and characterised a series of cosmids covering the $5^{\prime}$ and $3^{\prime}$ ends of the genomic sequence of the RB1 gene which can be used in FISH analysis of chromosomes from $\mathrm{Rb}$ patients.

\section{Materials and methods}

ANALYSIS OF COSMIDS

Since plasmid sequences would cross react with the cosmid vector in hybridisation experiments using the gridded filter, the $3.8 \mathrm{R}$ and $1.8 \mathrm{M}$ probes were isolated by electrophoresis and purified using the 'Geneclean' procedure. The gridded filters, provided by the ICRF Genome Analysis Laboratory, were hybridised in Church buffer overnight with the probe radiolabelled by oligonucleotide extension as described by Feinberg and Vogelstein. ${ }^{11}$ DNA was prepared from cosmids using standard alkali-lysis procedures ${ }^{12} ; 100 \mu \mathrm{g} / \mathrm{ml}$ RNAase was added and incubated at $37^{\circ} \mathrm{C}$ for 45 minutes and DNA purified by phenol/chloroform extraction. The cosmid DNA was finally precipitated using two volumes of ethanol and resuspended in approximately $200 \mu \mathrm{TE}$.

\section{FLUORESCENCE IN SITU HYBRIDISATION}

Cosmid DNA (approximately $1 \mu \mathrm{g}$ per reaction) was labelled with biotin-14-dATP (Gibco) using the Bionick kit (Gibco) which introduces biotinylated nucleotides into the cosmid DNA by nick translation with DNAase. The reaction was allowed to proceed for one hour at $16^{\circ} \mathrm{C}$ followed by one hour at $37^{\circ} \mathrm{C}$ as described by Pinkel et al..$^{13}$ Repetitive sequences in the cosmid were competed out with CotI DNA (Gibco) as described by the manufacturers. Hybridisation was allowed to
Received 13 August 1993 Revised version accepted fo publication 10 November 1993 


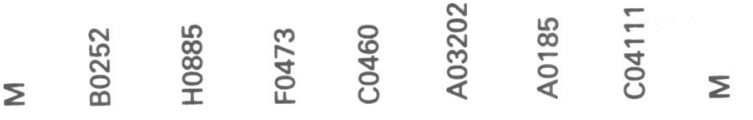

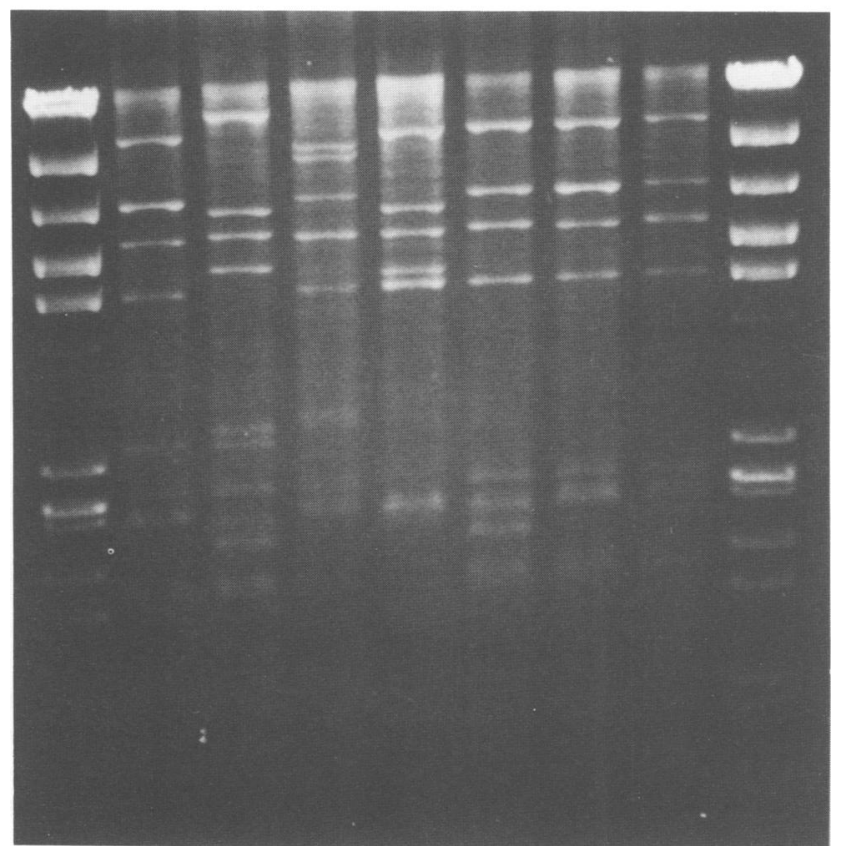

Figure 1 HindIII restriction band patterns of cosmids spanning the $3^{\prime}$ end of the RB1 gene.

proceed for 24 to 72 hours in a humidified chamber at $37^{\circ} \mathrm{C}$. The slides were then washed three times in $50 \%$ formamide/ $2 \times$ SSC followed by three washes in $2 \times$ SSC both at $42^{\circ} \mathrm{C}$. The slides were then prepared for immunological detection of the biotinylated probe by washing in $4 \times \mathrm{SSC} / 0.05 \%$. Chromosome spreads were then viewed using a CCD camera (Photometrics) and the Smartcapture software (Digital Scientific, Cambridge).

\section{Results}

Flow sorted chromosomes were used to create a cosmid library (C107) for human chromosome 13, the details and characterisation of which will be presented elsewhere (Nizetic et $a l$, submitted). These libraries are gridded on nylon membranes at high density for screening by hybridisation. The human RB1 cDNA is $4.7 \mathrm{~kb}$ long and contains an EcoRI site which produces two fragments, $0.9 \mathrm{~kb}$ and $3.8 \mathrm{~kb}$ long, termed $0.9 \mathrm{R}$ and $3.8 \mathrm{R}$ respectively ${ }^{8}$ The 3.8R fragment covers exons 9-27 and behaves

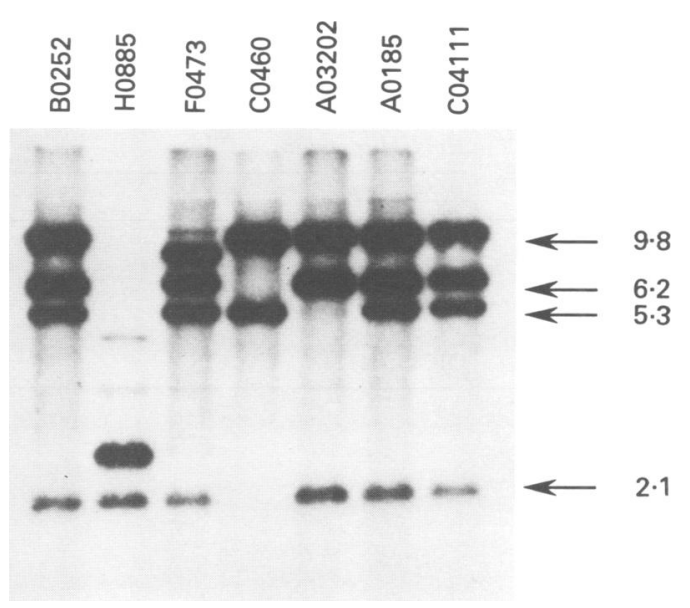

Figure 2 Autoradiograph of HindIII digested cosmid $D N A$ probed with $3.8 R$. Although the $2 \cdot 1 \mathrm{~kb}$ fragment corresponding to exon 27 of RB1 is present in HO885, new bands are also seen, possibly suggesting internal rearrangement of this cosmid.

as a unique sequence probe although, when hybridised to total genomic DNA digested with HindIII for example, produces hybridising bands on the autoradiograph which largely correspond to the $3^{\prime}$ end of the gene covering exons 18-27. When we screened the gridded chromosome 13 library with $3 \cdot 8 \mathrm{R}$, seven individual cosmids were identified and recovered. HindIII digests of DNA from these cosmids (fig 1) show that each has restriction fragments in common as well as a few which are unique. When these cosmids were probed with the 3.8R fragment all showed positive hybridisation, although it was clear that only certain bands hybridised in some cosmids compared with others (fig 2). From an analysis of the hybridisation pattern it was possible to construct an overlap map of these cosmids which extends into the $3^{\prime}$ untranslated region of the gene and into the large $(70 \mathrm{~kb})$ intron $^{14}$ between exons 17 and 18 (fig 3). Cosmid HO885 showed an abnormal hybridisation pattern which was not analysed further since the remaining overlapping cosmids proved adequate for the FISH analysis. Curiously, only the exons at the $3^{\prime}$ end of the gene were present, possibly because the hybridisation to exons $9-17$ is only weak and so were not identified in the primary screen. This is consistent with Southern blot hybridisation experiments where the restriction fragments which hybridise strongly are those encompass-

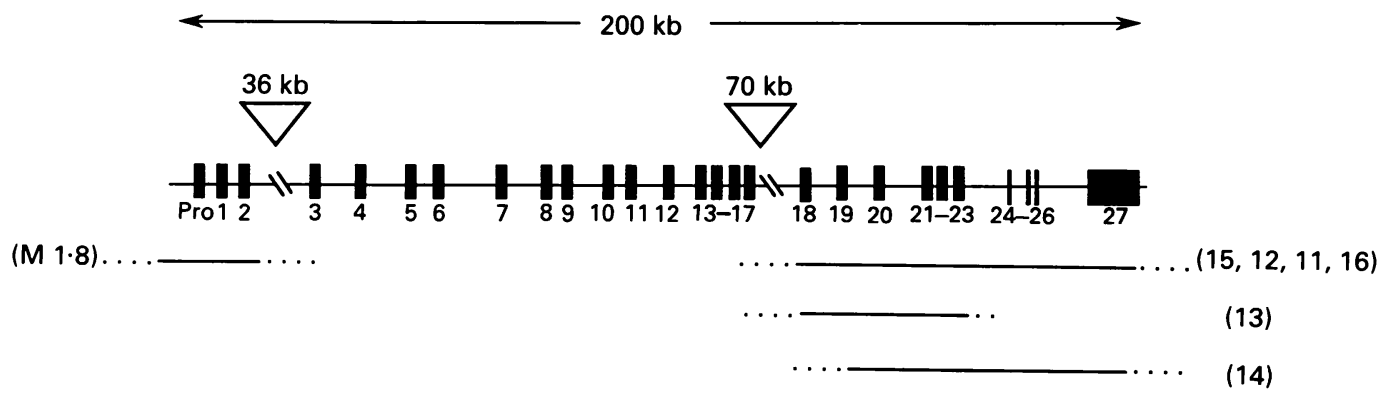

Figure 3 Physical map of the $3^{\prime}$ end of RB1 showing the relative location of the seven cosmids, 11-16. The solid lines represent regions of the gene confirmed by Southern blotting to be in the particular cosmid and the dotted line indicates the probable extensions. 
Table 1 Summary of hybridisation for each of the seven cosmids using the $3.8 R$ probe. The reference number refers to the ICRF reference library database and the cosmid number is the laboratory quick reference code

\begin{tabular}{llllll}
\hline & \multicolumn{3}{l}{ HindIII fragments } & & \\
\cline { 2 - 5 } Cosmid & Reference No & $5.3 \mathrm{~kb}$ & $9.8 \mathrm{~kb}$ & $6 \cdot 2 \mathrm{~kb}$ & $2 \cdot 1 \mathrm{~kb}$ \\
\hline RB $\cos 15$ & C108 B0252 & + & + & + & + \\
RB $\cos 16$ & C108 F0473 & + & + & + & + \\
RB $\cos 13$ & C108 C0460 & + & + & + & + \\
RB $\cos 14$ & C108 A03202 & + & + & + & + \\
RB $\cos 12$ & C108 A0185 & + & + & + & + \\
RB $\cos 11$ & C108 C0411 & + & + & + & + \\
\hline
\end{tabular}

Table 2 Summary of PCR results for exons 1 and 2 for each of the five cosmids identified by their ICRF database reference number

\begin{tabular}{lll}
\hline & Exon 1 & Exon 2 \\
\hline C 108 E135 & + & + \\
C 108 F1154 & + & + \\
C 108 F266 & + & + \\
C 108 G291 & + & + \\
C 108 H170 & + & - \\
\hline
\end{tabular}
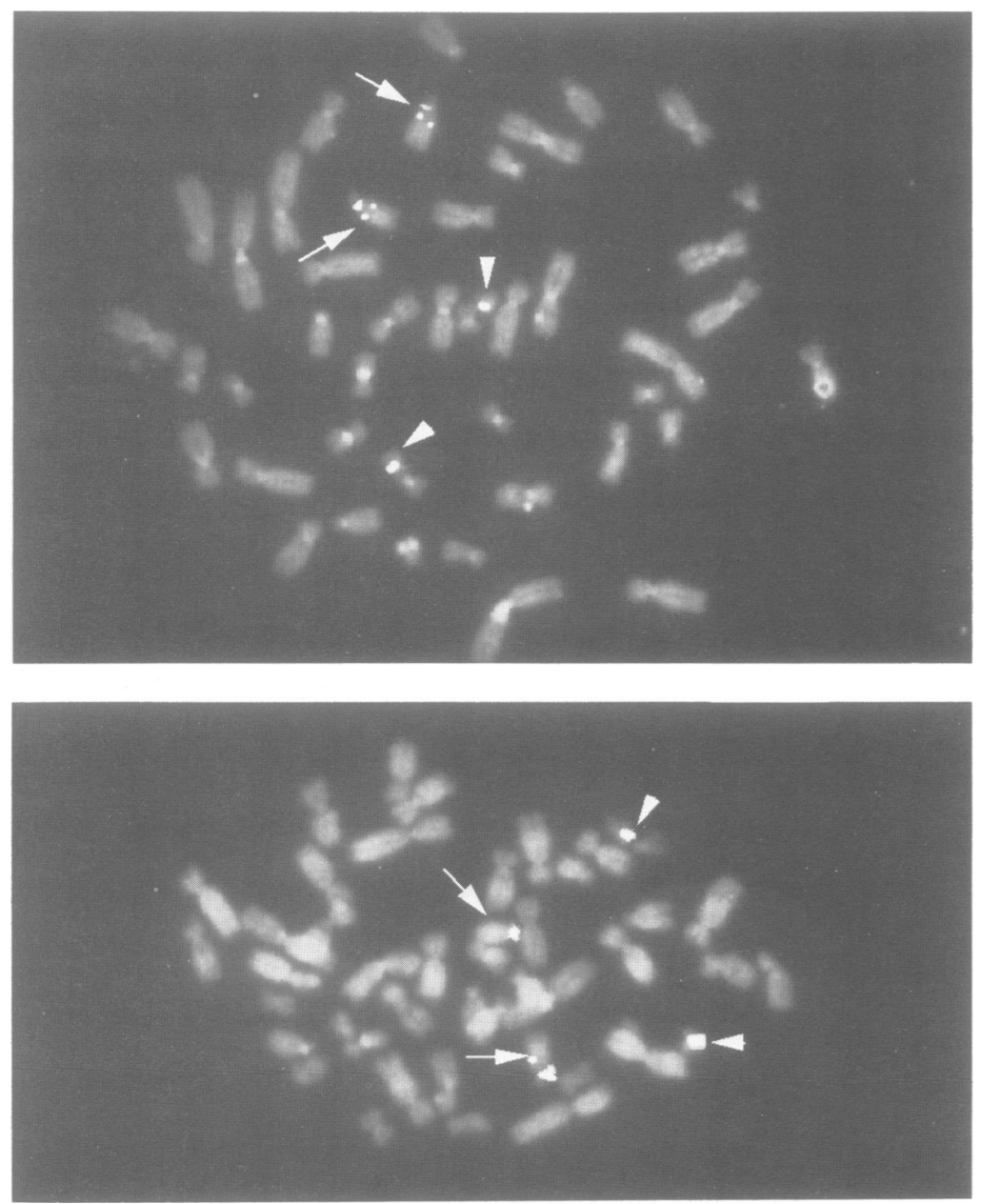

Figure 4 FISH analysis of normal metaphase chromosomes (top) using cosmid G291 showing hybridisation to two homologues of chromosome 13 (arrows). The centromeres of chromosome 13 have been identified using an $\alpha$ satellite probe, the signal from which lies above the RB1 specific sequence on each homologue. This $\alpha$ satellite also cross reacts with chromosome 21 and two small acrocentric chromosomes also show hybridisation signal above their centromeres (arrow heads). Chromosome analysis of GOS $115 \mathrm{~A}$ (bottom) is shown where the two homologues of 13 are identified by strong centromeric staining (closed arrows) but only one homologue shows hybridisation signa in the 14 region. The satellites at the centromeres of both copies of chromosome 21 are also seen (arrowheads). ing exons 18-27. The absence of exons 9-17 in these cosmids was confirmed using PCR and the oligonucleotides described by Hogg et al. ${ }^{15}$ Details of the cosmids from the $3^{\prime}$ end of the gene, together with their reference library numbers, are given in table 1.

The exons of the RBl gene cluster in three distinct groups separated by two large introns. ${ }^{16}$ We were unable to identify cosmids covering the central part of the gene. The $0.9 \mathrm{R}$ fragment covers the first eight exons of $\mathrm{RB} 1^{17}$ and contains repetitive elements, which makes it difficult to use directly in hybridisation experiments. In order to isolate cosmids from the 5 ' end of the gene we used a unique sequence DNA probe, $M 1.8,{ }^{18}$ located in intron 2 of RB1. From this screen five cosmids were isolated all of which were shown to contain exons 1 and 2 using PCR (table 2) and their location within the RB1 gene is shown in fig 3.

The seven cosmids from the $3^{\prime}$ end of the gene and the five cosmids from the $5^{\prime}$ end were used in FISH analysis using metaphase chromosomes from normal persons and they all produced a positive signal exclusively in the q14 region of chromosome 13 (fig 4). This strongly suggests that none of these cosmids is chimeric. To determine whether these cosmids could be used to identify chromosome deletions, metaphase chromosomes were prepared from a lymphoblastoid cell line, GOS 115A, derived from the patient discussed by Cowell et $a l^{6}$ with a subband deletion of $13 \mathrm{q} 14$. Hybridisation was only observed on one chromosome 13 homologue in each metaphase spread (fig 4).

During the course of this analysis two patients were referred to us for ESD analysis who carried deletions involving $13 \mathrm{q} 14$. These patients were karyotyped because they showed dysmorphic features and developmental delay. One patient showed $\operatorname{del}(13)(\mathrm{q} 12 \mathrm{q} 14.1)$ the other del (13)(q14q22). In situ hybridisation showed that only one of the chromosome 13 homologues showed hybridisation with the RB1 cosmids in both cases, confirming that the RB1 gene was included in the deletion. Since this diagnosis the child with the $\operatorname{del}(13)(q 12 q 14.1)$ has developed tumours but the other patient has not yet, although she is still only 5 months old. We have noted in the past $^{4}$ that the majority of deletion 13 cases tend to have a later onset of disease than persons carrying the hereditary predisposition owing to point mutations in the RB1 gene. Clearly the del(13)(q14q22) patient must still be screened ophthalmologically for the forseeable future.

\section{Discussion}

The series of cosmids described here can clearly be used to identify $\mathrm{Rb}$ patients with constitutional deletions of the RB1 gene. Until now, deletions have traditionally been identified either through cytogenetic $\mathrm{G}$ banding analysis, which can be very subjective when small deletions are involved, or by the demonstration that patients have reduced red cell ESD levels. ${ }^{419}$ The ESD gene, which lies proximal to $R B 1,{ }^{20}$ is at least $200 \mathrm{~kb}$ away ${ }^{21}$ and possibly even further. Thus, deletions of RB1 which do not extend as 
far as ESD would not be detected by ESD quantitation. Deletions in $\mathrm{Rb}$ patients seem to fall into two classes ${ }^{4}$; those with $13 \mathrm{q} 12-\mathrm{q} 14$ deletions and those where the proximal breakpoint lies in 13q14 and the deletion extends distally. From this observation alone it cannot be determined whether RB1 is lost as a result of the deletion. Because these patients usually have mental retardation many of the deletions are identified in the patient before tumours have developed. At this stage the question, therefore, is whether the $13 \mathrm{q} 12-\mathrm{q} 14$ deletions extend as far as RB1 or, when the proximal breakpoint is in 13q14, is it centromeric to RB1?

The RB1 gene lies on the chromosome with the $5^{\prime}$ end towards the centromere. ${ }^{22}$ Thus, patients presenting with deletions involving proximal parts of the chromosome should be analysed with the M1.8 cosmids and patients with deletions extending distally should be analysed with the $3^{\prime}$ cosmids. Failure of any of these cosmids to hybridise means that the patient has lost part, or all, of the RBl gene and is therefore "at risk" of tumorigenesis and should therefore undergo repeated ophthalmological analysis. Clearly, in routine applications of this technology, representatives from most of the cosmids should be used and a sufficient number of metaphase spreads analysed to confirm that a deletion exists. This type of analysis should supersede ESD quantitation studies which are time consuming to set up especially for small sample numbers, particularly since quality controls must be run before each new set of samples are analysed. ${ }^{19}$ The other advantage of FISH analysis over ESD quantification is that it will detect deletions which do not extend to the ESD locus. One such example was reported by Cowell et $a l^{23}$ where the deletion breakpoint lay between ESD and RB1. ${ }^{20}$ The other advantage of FISH is that the subjectivity associated with metaphase chromosome analysis is removed, particularly when the deletions are small and confined to the $13 \mathrm{q} 14.3$ region. In future, therefore, $\mathrm{RB} 1$ deletions can be detected by technicians not trained in $G$ banding analysis since, by using the $\alpha$ satellite probe which recognises chromosomes 13 and 21 , it is relatively easy to identify the two homologues of chromosome 13 as we have shown. A recent report by Kallionemi et $a l^{4}$ used 14 phage lambda clones covering RB1 and FISH analysis which could be used to identify RB1 deletions. We feel that cosmids have advantages over phage in that fewer clones are needed to span the gene and it is far simpler to prepare DNA from them. It is unlikely that FISH will detect small intragenic deletions, however, since the cosmids or lambda clones will span the deletion and hybridisation may not be compromised.

The RBl gene is also deleted and rearranged in a variety of other tumours including osteosarcoma ${ }^{8}$ breast tumours, ${ }^{25}$ small cell lung cancer, ${ }^{26}$ and $\mathrm{B}$ cell leukaemia. ${ }^{27}$ In the latter case particularly, chromosome morphology from tumour cells may not be of sufficient quality to identify small deletions but the panel of cosmids described here will clearly assist in the evaluation of allele loss in those tumours where conventional cytogenetics may have been equivocal.

1 Sparkes RS, Murphree AL, Lingua RW, et al. Gene for hereditary retinoblastoma assigned to human chromosome 13 by linkage to esterase-D. Science 1983;219:971-3.

2 Lele KP, Penrose LS, Stallard HB. Chromosome deletion in a case of retinoblastoma. Ann Hum Genet 1963;27:171-4.

3 Yunis JJ, Ramsay N. Retinoblastoma and sustained deletion of chromosome 13. Am f Dis Child 1978;132:161-3.

4 Cowell JK, Hungerford J, Rutland P, Jay $M$. Genetic and $\mathrm{D}$ levels and mental retardation from a survey of 500 individuals with retinoblastoma. Ophthal Paediatr Genet individuals with

5 Motegi T, Komatsu M, Minodo K. A recognisable pattern of the midface of retinoblastoma patients with intersitial deletions of 13q. Hum Genet 1983;64:160-62.

6 Cowell JK, Thompson E, Rutland P. The need to screen al retinoblastoma patients for esterase-D activity; detection of submicroscopic deletions. Arch Dis Child 1986;62:8-11.

7 Onadim Z, Hungerford J, Cowell JK. Follow-up of retinoblastoma patients having prenatal and perinatal predictions for mutant gene carrier status using intragenic polymorphic probes from the RBl gene. Br $\mathcal{f}$ Cancer polymorphic probe

8 Friend SH, Bernards R, Rogelj S, et al. A human DNA segment with properties of the gene that predispose to retinoblastoma and osteosarcoma. Nature 1986;323:643-6.

9 Hogg A, Bia B, Onadim Z, Cowell JK. Molecular mechanisms of oncogenic mutations in tumours from patients with bilateral and unilateral retinoblastoma. Proc Nat Acad Sci USA 1993;90:7351-5.

10 Onadim Z, Hogg A, Cowell JK. Mechanisms of oncogenesis in patients with familial retinoblastoma. $\mathrm{Br} \mathcal{F}$ Cancer 1993;68:958-64.

11 Feinberg AP, Vogelstein B. A technique for radiolabeling DNA restriction endonuclease fragments to high specific activity. Anal Biochem 1983;132:6-13.

12 Sambrook J, Fritsch EF, Maniatis T. Molecular cloning: a aboratory manual. 2nd ed. Vol 3. Cold Spring Harbor: Cold Spring Harbor Laboratory Press, 1989.

13 Pinkel D, Landegent J, Collins C et al. Fluorescence in situ hybridization with human chromosome-specific libraries; deletion of trisomy 21 and translocations of chromosome 4. Proc Natl Acad Sci USA 1988;85:9138-42.

14 McGee TL, Yandell DW, Dryja TP. Structure and partial genomic sequence of the human retinoblastoma susceptibility gene. Gene 1989;80:119-28.

15 Hogg A, Onadim Z, Baird PN, Cowell JK. Detection of heterozygous mutations in the RBl gene in retinoblastoma patients using single-strand conformation polymorphism analysis and polymerase chain reaction sequencing. Oncogene 1992;7:1445-51.

16 Friend SH, Horowitz JM, Gerber MR, et al. Deletions of a DNA sequence in retinoblastomas and mesenchymal tumours: organization of the sequence and its encoded protein. Proc Natl Acad Sci USA 1987;84:9059-63.

17 Bookstein R, Lee EYH, To H, et al. Human retinoblastoma susceptibility gene: genomic organization and analysis of heterozygous intragenic deletions mutants. Proc Nat Acad Sci USA 1988;85:2210-14

18 Wiggs J, Nordenskjeld $M$, Yandell $D$, et al. Prediction of the risk of hereditary retinoblastoma using DNA polymorphisms within the retinoblastoma gene. $N$ Engl $f \mathrm{Med}$ 1988;318:151-7.

19 Cowell JK, Rutland P, Jay M, Hungerford J. Deletions of the esterase-D locus from a survey of 200 retinoblastoma the esterase-D locus from a survey

20 Mitchell CD, Cowell JK. Molecular evidence that the esterase-D gene lies proximal to the retinoblastoma susceptibility locus in chromosome region 13q14. Hum Gene 1988;81:57-60.

21 Ford GM, Gallie BL, Phillips RA, Becker AJ. A physica map around the retinoblastoma gene. Genomics 1990;6:284-92.

22 Mitchell CD, Cowell JK Predisposition to retinoblastoma due to a translocation within the 4.7R locus. Oncogene $1989 ; 4: 253-7$.

23 Cowell JK, Hungerford J, Rutland $\mathrm{P}$, Jay $\mathrm{M}$. A chromosomal breakpoint which separates the esterase-D and retinoblastoma predisposition loci in a patient with del(13)(q14-q31). Cytogenet Cell Genet 1987;27:27-31.

24 Kallioniemi A, Kallioniemi OP, Walden FM, et al. Detec tion of retinoblastoma gene copy number in metaphase chromosomes and interphase nuclei by fluorescence in situ hybridisation. Cytogenet Cell Genet 1992;60:190-3.

25 Lee EYHP, To H, Shew JH, Bookstein R, Scully P, Lee WH. Inactivation of the retinoblastoma susceptibility gene in human breast cancers. Science 1988;241:218-21.

26 Hensel CH, Hsieh CL, Gazdar AF, et al. Altered structure and expression of the human retinoblastoma susceptibiand expression of the human retinoblastoma susceptibility gene in small

27 Hawthorn LA, Chapman R, Oscier D, Cowell JK. The consistent 13q14 translocation breakpoint seen in chronic B-cell leukaemia (BCLL) involves the deletion of the D13S25 locus which lies distal to the retinoblastoma predisposition gene. Oncogene 1993;8:1415-19. 